\title{
Biología, reificación y transdisciplina: Hacia una visión crítica de las ontologías y los conflictos científicos
}

\author{
Biology, Reification and Transdisciplinarity: \\ Towards a Critical Approach of Scientific Ontologies and Conflicts \\ Octavio Valadez-Blanco ${ }^{\dagger}$ \\ Fabrizzio Guerrero McManus ${ }^{\ddagger+}$
}

\begin{abstract}
Resumen
Los problemas que analiza la Biología son presentados con frecuencia como problemas complejos que exigen una articulación inter-transdisciplinaria. En este trabajo planteamos la necesidad de evaluar cómo construimos la ontología de lo biológico y cómo la conocemos sin que por ello quede olvidada la difuminación creciente de la figura del experto y su fusión -al menos parcial- con otras figuras como el tecnólogo, el entrepeneur, la activista, la gestora, etc. Para ello, recuperamos y ampliamos la categoría de reificación desde diversas tradiciones con las cuales es posible articular un diálogo con la metafísica, la epistemología, la epistemología social, los estudios sociales y culturales y las preocupaciones políticas, sociales y económicas de la biología. Con este aparato crítico proponemos una serie de principios y postulados que puedan nutrir y ampliar la discusión sobre las investigaciones inter-transdisciplinarias tanto en sus versiones semánticas como en aquellas centradas en las práctica-políticas.
\end{abstract}

Palabras clave: reificación - experticia - transdisciplina - axiología - filosofía de la biología

\begin{abstract}
The problems analyzed by biologists are most often presented as complex and requiring inter-transdisciplinary approaches. In this paper we claim that it is necessary to evaluate how we build ontologies within biology and how we can know them, especially given the current blurring of the figure of the expert and -at least its partial fusion with other roles such as the technologist, the entrepreneur, the activist, the manager, etc. To achieve this, we recover and expand the category of reification and engage in a dialogue with metaphysics, epistemology, social epistemology, social and cultural studies and political, social and economic concerns of biology. With this critical approach we endorse several principles able to nurture and expand the discussion on the inter-transdisciplinary research in both their semantic versions and those focusing on the practical and political aspects of science.
\end{abstract}

Keywords: reification - expertise - transdisciplinary - axiology - philosophy of biology

\footnotetext{
* Recibido: 3 de Junio de 2014. Aceptado con revisiones: 13 de Agosto de 2014.

† Doctorando del Posgrado en Filosofía de la Ciencia, UNAM. Para contactar al autor, por favor, escribir a: hoktavius@yahoo.com.mx.

* Centro de Investigaciones Interdisciplinarias en Ciencias y Humanidades, UNAM.

+ Agradecemos a Rasmus Winther y a Mario Casanueva. Proyecto y Seminario de investigación Representación y Modelización del Conocimiento Empírico con financiamiento del CONACYT (Consejo Nacional de Ciencia y Tecnología) Clave CB-2012/182084. Metatheoria 5(1)(2014): 113-126. ISSN 1853-2322.

(C) Editorial de la Universidad Nacional de Tres de Febrero. Publicado en la República Argentina.
} 


\section{Introducción}

La biología abarca un espectro amplio de niveles de organización que van desde las macromoléculas -o, según la nueva biología cuántica, las partículas subatómicas- hasta la biosfera. A nivel temporal, lidia con procesos que van de la casi instantaneidad hasta los eones que se remontan al comienzo del planeta Tierra. Esto hace de la biología una ciencia metodológica, axiológica y disciplinariamente compleja. Con respecto a lo primero, la biología requiere ser capaz de abordar preguntas que la aproximan tanto a la química y a la física como a la historia, la sociología y la antropología.

Axiológicamente, es claro que su relevancia económica, social y política es indudable si atendemos a las aplicaciones y consecuencias de la biomedicina, las ciencias ambientales, la biología sintética y la biotecnología; sin duda que esto demanda de la biología una capacidad de interlocución con la medicina, la economía, la ciencia política y la administración tanto pública como privada. Sin embargo, conjuntamente con estas dimensiones aplicadas, hay en la biología preguntas teóricas cuyas consecuencias en esos planos son difíciles de anticipar. No sería, por tanto, trivial el dar cuenta de los fines y valores que la orientan.

Por último, la biología es una ciencia disciplinariamente compleja porque, a pesar de tener dos grandes cuerpos teóricos que en cierto sentido le dan identidad -la Teoría Evolutiva y la Biología Molecular-Celular-, lo cierto es que su ámbito de acción no se circunscribe a lo vivo sino que engloba tanto a aquello que lo constituye como a aquello que lo rodea. De ahí que resulte difícil demarcar las fronteras de la biología.

Por todo lo anterior, debe resultar claro que la biología es, en sí misma, una ciencia que ya es transdisciplinaria y, sin embargo, no por ello es autosuficiente en su capacidad tanto de abordar preguntas concretas como de lidiar con problemáticas claramente situadas. En otras palabras, en la biología el acto de representar y el acto de intervenir están íntimamente conectados.

Curiosamente, es este último punto lo que apuntala la necesidad de incluir a la filosofía -in extenso y no únicamente a la filosofía de la biología- como parte del ecosistema disciplinario de la biología misma. Esto es así porque la vinculación entre representación e intervención demanda el atender a las prácticas científicas reconociendo que oposiciones clásicas como las de contexto de descubrimiento vs. contexto de justificación, racionalidad teórica vs. racionalidad práctica o ciencia básica vs. ciencia aplicada no admiten ya una lectura que las contraponga como absolutos mutuamente excluyentes e infranqueables.

Sin embargo, estas vinculaciones avizoran riesgos que merecen una discusión filosófica que nos permita erigir nuevos conceptos que guíen nuestra exploración y nuestra intervención de un mundo que habitamos y que buscamos comprender. Valgan aquí dos ejemplos que ilustran lo que hemos buscado expresar.

Primer ejemplo. Pensemos en dos conceptos que hoy resultan ineludibles tanto para la bioeconomía como para las ciencias ambientales dedicadas a la conservación, restauración y manejo sostenible de los ecosistemas: los servicios ambientales y los servicios evolutivos. Los primeros nos remiten a todos los beneficios y utilidades que la humanidad, o una sección de ésta, recibe de la Naturaleza; por ejemplo, producción de oxígeno, captura de carbono, reciclaje del agua, etc. Los segundos, por otro lado, nos remiten a la utilidad o beneficio potencial de la evolucionabilidad de las poblaciones, especies o comunidades; por ejemplo, su capacidad de adaptarse a nuevas plagas.

En ambos casos, el término "servicio" pretende hacer conmensurable lo biológico con lo económico de tal suerte que tanto unos como otros servicios ofrecen una suerte de producción ecomediada en la que no hay trabajo humano involucrado. Al conceptuar de esta forma a lo biológico, se le otorga un valor que es traducible en un valor económico compatible con los sistemas de producción contemporáneos con la esperanza de que ello permita la creación de mecanismos de conservación, restauración o manejo, al interior de las así llamadas nuevas economías verdes, que serían compatibles con, y por ende, subsumibles bajo el Capitalismo de principios de milenio. 
Como puede verse, la búsqueda de una conmensurabilidad entre lo biológico y lo económico con fines de conservación, restauración o manejo demanda identificar entidades y capacidades claves que puedan ser protegidas, imitadas, controladas o administradas. Aquí se presenta, por tanto, un riesgo que no es menor, a saber, la posibilidad de identificar de forma incorrecta a dichas entidades y capacidades, por un lado, y la forma en la cual éstas emergen, interactúan y evolucionan, por otro. Así también, vale la pena preguntar acerca de la concepción de valor que subyace a esta aproximación en la cual la naturaleza es concebida como un objeto útil al cual se le puede valorar en un sentido compatible con la economía.

Segundo ejemplo. En años recientes se ha ido gestando un tipo de interacción entre la biología, la química, la física, la informática, las ciencias cognitivas y las ciencias de materiales que no puede caracterizarse ni como una aproximación interdisciplinaria o transdisciplinaria ni bajo un modelo filosófico unificacionista (Friedman 1974, Kitcher 1989) o integracionista (Mitchell 2003). Hablamos aquí de la ya famosa Convergencia Nano-Bio-Info-Cogno (Bainbridge 2006), es decir, de la creación de un Campo tecnocientífico e industrial en el que confluyen tanto las herramientas teóricas como los desarrollos técnicos e industriales de las nanociencias, la biotecnología, las ciencias de la información y las ciencias cognitivas.

Lo que une a todos los campos partícipes es, por un lado, una férrea convicción materialista, tanto en el sentido filosófico como en el sentido vulgar de esta palabra, como una aproximación deudora tanto de una visión mecanística de la materia como de una visión inspirada en los modelos de redes. Evidentemente el afán de este campo es intervenir a nivel molecular en ámbitos medicalizados que se relacionan tanto con la salud como con la posibilidad de construir cuerpos humanos mejorados. Asimismo, buscan intervenir en diversos aspectos como los serían los problemas ambientales, las tecnologías del manejo y almacenamiento de la información y en la producción y distribución de energía.

De nuevo, este ejemplo ilustra que la medida en la cual se juzguen como convergentes los campos Nano, Bio, Info y Cogno depende del tipo de ontologías que se ofrecen en dichas áreas, es decir, en el tipo de entidades, capacidades y relaciones que se postulan como existentes o relevantes. Igualmente depende de las dimensiones instrumentales de dichas ontologías ya que no todas serán proclives a guiar la intervención humana con la misma eficacia. Debe ser claro que el riesgo de caracterizar erróneamente uno de estos campos puede llevar a un fracaso estruendoso tanto académica como financieramente. Por último, este ejemplo deja clara la relación que existe entre axiología, experticia y ontología, por un lado, y entre todas estas y la dimensión económico-social de la tecnociencia, por otro.

Ahora bien, lo que ilustramos con los dos ejemplos anteriores es la importancia de erigir conceptos capaces de posibilitar una reflexión filosófica acerca de una biología cuyas ontologías van del instante a lo eterno, atravesadas en todos los tiempos y niveles por la pregunta de cómo individuar, demarcar y delimitar entidades, capacidades y relaciones cuya relevancia excede lo teórico; en suma, nuestro objetivo es ofrecer una propuesta en la cual podamos reflexionar acerca de cómo construimos la ontología de lo biológico y cómo conocemos dicha ontología sin que por ello quede olvidada una dimensión cada vez más inescapable de esta disciplina: la difuminación de la figura del experto y su fusión -al menos parcial- con las figuras del tecnólogo, el entrepeneur, la activista, la gestora, etc.

Creemos que el concepto marxista de reificación ofrece un punto privilegiado para comenzar a erigir un aparato conceptual que recupere la creciente articulación de la metafísica, la epistemología, la epistemología social, los estudios sociales y culturales y las preocupaciones políticas, sociales y económicas que buscan pensar a la biología como una ciencia que se lleva a cabo desde perspectivas situadas, engarzadas en redes culturales y económicas, y motivada por valores individuales y grupales.

El riesgo que anticipamos, ya mencionado, de dejar de lado un ejercicio como éste, posiblemente inacabable pero no por ello menos importante, se traduce en perder de vista que el esfuerzo de explorar las fronteras de la biología, sin atender al contexto del sujeto que produce, circula y consume al conocimiento es condenarnos a pasar por alto las imbricaciones entre representación e intervención, entre conocer y transformar. 
Por tal motivo este artículo se estructura de la siguiente manera. En una primera sección ofrecemos una breve reseña del concepto de reificación y una tipología que busca expandir su aplicabilidad. Posteriormente, abordaremos los desafíos que enfrentan hoy los modelos inter y transdisciplinarios y cómo creemos que éstos pueden ser abordados al incluir esta noción. Por último, concluimos destacando los elementos centrales de esta reflexión.

\section{Reificación}

El concepto de reificación figura en numerosos textos al interior de la filosofía de la ciencia. Aparece, por ejemplo, en discusiones sobre la construcción social de la raza o el género (vease Kaplan \& Winther 2012, Winther 2014b), en temas asociados a la idea misma de una naturaleza humana capaz de dar cuenta de regularidades transculturales o transhistóricas (por ejemplo, los debates en torno al coeficiente intelectual [CI] y su supuesta heredabilidad) e, incluso, figura en acaloradas discusiones teóricas acerca de cuál ontología es más apropiada para la biología, si una ontología de entidades o una ontología de procesos (por ejemplo Dupré 2012). En todos estos casos los filósofos de la ciencia emplean el término 'reificación' para desbrozar las presuposiciones que sostienen a nuestros modelos, explicaciones y teorías con el afán de revelar la parcialidad de las mismas y su capacidad de invisibilizar descripciones alternativas de un mismo fenómeno que bien pueden resultar mucho más enriquecedoras.

$\mathrm{Al}$ interior de la filosofía de la biología la categoría puede rastrearse en los trabajos de los filósofos y biólogos evolutivos Richard Lewontin, Richard Levins, Steven Rose y asociados (Levins 2006, Levins \& Lewontin 1987) quienes la usaron para señalar las deficiencias epistemológicas del determinismo biológico y del genocentrismo a la hora de explicar la evolución biológica, en general, y la evolución humana, en particular. La idea central de dichos autores radicaba en señalar que la reificación es básicamente el olvido de un proceso histórico de abstracción (Levins \& Lewontin 1987), esto es, consiste en pasar por alto los elementos convencionalistas que subyacen a todo diseño experimental y a toda taxonomía conceptual. Las consecuencias de dicho olvido se traducen en el ocultamiento de las contingencias históricas que hicieron posible el desarrollo de una disciplina tanto en sus dimensiones teóricas como prácticas; asimismo, se traducen en la creación de una ideología -en tanto falsa conciencia- acerca de los fenómenos bajo estudio.

Así, por ejemplo, se considera que la naturalización de la raza, el género o la orientación sexual pasan por alto el proceso histórico que llevó a que dichos conceptos surgieran y terminaran por convertirse en identidades que diversos seres humanos han retomado. Algo similar ocurre cuando se pasa por alto que las diferencias en el CI obedecen en gran medida a diferencias socioeconómicas y culturales y no a atributos intrínsecos.

Ahora bien, el filósofo Rasmus Winther (Winther 2006a, 2006b, 2011a, 2011b, 2014a, 2014b, Kaplan \& Winther 2012) ha comenzado un extenso estudio acerca de la reificación en las ciencias. Su punto de partida ha sido justamente el modo en el cual Lewontin y Levins han concebido a la reificación. De acuerdo con Winther la reificación es ante todo un tipo de abstracción perniciosa y de carácter metonímico en la cual lo concreto es reemplazado por representaciones abstractas de ese mismo concreto. Bajo esta acepción, la reificación es una práctica epistémica asociada a representaciones abstractas que buscan representar el mundo pero que terminan por equipararse a él. El elemento pernicioso no es, por tanto, intrínseco a la representación sino a la pragmática que rige el uso de dicha representación; es decir, hay un uso pernicioso si y sólo si la representación es concebida como omnicomprensiva por parte del productor o usuario de la misma.

Este último punto es importante por dos razones. Primero, la abstracción es inescapable en un mundo ontológicamente complejo que, además, está poblado por seres temporal, espacial y computacionalmente limitados. En ese sentido toda posibilidad de conocer y actuar eficazmente en dicho mundo descansa en nuestra capacidad de generar representaciones idealizadas del mismo. Sin embargo, esto no justifica pasar por alto la complejidad del mundo o la limitación de sus sujetos. Así, 
la crítica a la reificación no es una crítica a la abstracción sino a ciertas dimensiones pragmáticas de la misma.

Segundo, al entender a la reificación como un tipo específico de abstracción que se caracteriza por sus dimensiones metonímicas y perniciosas se le distingue de otro tipo de procesos cognitivos mediados por nuestra intencionalidad colectiva y que, en cierto sentido, también ontologizan nuestras abstracciones. Nos referimos aquí a la constitución de entidades y propiedades sociales que hoy estudia la metafísica de lo social. En dichos procesos de constitución se le otorga realidad a entidades como el Estado, las normas, el matrimonio, la identidad, etc. a través de un contrato social, i.e. de una acción colectiva coordinada en la cual un conjunto de representaciones socialmente distribuidas permiten la emergencia de ese famoso Tercer Mundo popperiano en el cual habitan entidades objetivas cuya existencia depende, sin embargo, del reconocimiento subjetivo de los seres humanos.

Por ende, la reificación aparece como el gemelo malvado de la constitución. Si la segunda crea mundos, la primera los reemplaza. Si la segunda añade y enriquece al mundo, la primera lo empobrece. Si la segunda añade entidades, propiedades y procesos causales, la primera los invisibiliza.

Lo anterior tiene una importante consecuencia. El término 'reificación' como hasta ahora lo hemos analizado tiene claros tintes normativos ya que implica una crítica a un uso pernicioso de una abstracción y remite a la necesidad de una terapéutica correctiva. Pero aquí surge una pregunta no explorada con gran profundidad: ¿quién puede denunciar la existencia de una reificación? En cierto sentido esta pregunta debiera resultar obvia ya que detectar una práctica perniciosa requiere de dos condiciones: a) ser afectado, o posicionarse negativamente frente a una práctica o abstracción, y b) tener cierto grado de experticia al interior de una práctica. Sin embargo, estas preguntas sugieren que, si bien cualquiera puede verse afectado por los efectos epistémicos, o sociales de las reificaciones, no cualquiera está en condiciones de señalar una reificación pero, incluso si ésta se detecta, no queda claro quién está en condiciones de denunciarla de forma eficaz.

Precisamente por estos últimos dos puntos es que consideramos que un análisis acerca del concepto de reificación al interior de la filosofía de la ciencia es meritorio. Más si tenemos en cuenta la forma en la cual la biología y las ciencias ambientales y cognitivas se han vuelto un espacio central en lo que respecta a la reflexión en torno a qué somos como especie, como civilización y cuál es el efecto que nuestra presencia ha tenido sobre el planeta. Creemos por ello que es necesario explorar de forma concienzuda la historia de dicho concepto para así recuperar la riqueza semántica del mismo.

Por ejemplo, podríamos rastrear el concepto en una tradición analítica donde sobresalen los trabajos recientes de Winther (2006a, 2006b, 2011a, 2011b, 2014a, 2014b), quien está altamente influenciado por William Wimsatt y por Richard Levins y Richard Lewontin; todos ellos, como se ha dicho, han definido a la reificación como el olvido del proceso histórico de abstracción. Por otro lado, para la tradición marxista y sus derivaciones en la teoría crítica, la categoría de reificación juega un papel central como una categoría que permite criticar a las ontologías que ocultan su historicidad (Bewes 2002, Dussel 1993, 2009, Honneth et al. 2012, Marx 1991). Así en la civilización capitalista la vida concreta y cualitativa de los seres humanos (expresada en la producción de sus necesidades, en el mundo del valor de uso) se fetichiza y reifica cuando ella se subordina y pretende explicarse sólo por el proceso de circulación, es decir por la lógica cuantitativa del valor y la ganancia.

Con estos dos ejemplos nos interesa señalar que, si bien dentro de la tradición analítica, ha habido la tentación de construir a la reificación como la concretización de lo abstracto y, por ende, concebir a la reificación dentro de la polaridad abstracto-concreto, lo cierto es que dentro de otras tradiciones filosóficas la noción de reificación se ha pensado bajo polaridades diferentes. Por ejemplo, se le ha pensado como una noción mucho más cercana a la sobredeterminación de una estructura por otra o de una parte hacia el todo, de una absolutización de aquello que está relacionado.

En ese sentido, bien podríamos sugerir que la reificación tomará diversas modalidades si opera bajo diversos estilos de racionalidad y de posicionamiento moral o normativo (Hacking 2009). La propia tradición analítica -y el propio Winther- parecerían ofrecer y aceptar esta diversidad. Pensemos, por ejemplo, en la sugerencia de Winther acerca de otros estilos de racionalidad. Él ha destacado el estilo composicional (Winther 2011b) y, más recientemente, un estilo histórico-narrativo propio de la 
sistemática biológica. En todo caso, ha sugerido que estos estilos operan con estrategias de abstracción y modelización previas. Si esto es el caso, uno no puede más que preguntarse si la reificación operara de maneras igualmente diferentes. La apuesta de este texto es que de hecho esta diversidad es el caso.

\subsection{La reificación y sus modalidades}

En esta sección proponemos una clasificación tentativa en la cual se reconocen cinco sentidos diferentes de reificación. Nuestra intención es traer luz al introducir una nomenclatura que esclarezca sus diversas modalidades. Primero, analizaremos lo que llamamos "reificación como concretización". Segundo, una acepción a la que llamamos "reificación mereológica". Tercero, una alternativa más, denominada "reificación analógica". Cuarto, una "reificación de procesos". Y, quinto y último, una "reificación implícita en prácticas".

El primer tipo, la reificación como concretización, se refiere fundamentalmente a la reificación de representaciones y opera en la polaridad abstracto-concreto. El segundo tipo, la reificación mereológica, opera bajo la oposición parte-todo y versa acerca de la atribución de propiedades a la unidad de análisis adecuada. La tercera clase de reificación, la analógica, no se establece entre una representación y lo representado ni entre una parte y un todo sino entre entidades igualmente concretas y que pertenecen a una misma clase; es por ello que el ejemplo de las relaciones de género resulta aquí tan ilustrativo ya que ni hombres ni mujeres, ni blancos ni negros, somos parte de un "todo" pero sí que pertenecemos a una misma clase: la especie humana. El cuarto sentido, la reificación de procesos, remite a casos en los cuales un producto viene a representar el proceso que lo generó. Finalmente, la reificación implícita busca visibilizar a las reificaciones que ocurren en la praxis y no así en las dimensiones representacionalistas antes mencionadas.

Nótese, desde luego, que no se pretende excluir la posibilidad de que hubieran usos de reificación no previstas por este análisis. Tampoco se pretende que no haya casos limítrofes en los cuales parecen operan varias de las nociones aquí propuestas.

Esta propuesta taxonómica emana tanto de una lectura histórica acerca de los diversos usos de este término como de un análisis conceptual acerca de la diversidad de usos con los que dicho término se encuentra. Deriva, por último, del reconocimiento de la pluralidad de estilos de razonamiento en la ciencia contemporánea y su urdimbre cultural y civilizatoria; pluralidad que implica una imposibilidad de capturar exitosamente este término de una manera igualmente proyectable a cada estilo.

Se reconoce, por ende, que si hay más de un estilo de racionalidad, con sus formas de abstraer y de modelizar, entonces probablemente haya también formas diferentes de reificar. Se sugiere en este sentido que la reificación mereológica, la reificación analógica y la reificación de procesos son formas de reificar en las cuales nos alejamos de la polaridad abstracto-concreto y nos adentramos en relaciones de parte-todo y de instancia/tipo. En estas diversas formas de reificar el énfasis cae, en el caso de la primera, en la importancia de reconocer cómo se da una relación de sobredeterminación entre un todo y sus partes al nivel de relaciones causales o constitutivas o, en el caso de la reificación analógica, en la forma en la cual un ejemplar particular se constituye como el paradigma de conmensurabilidad para otras instancias de esa clase. En el caso de la reificación de procesos nos acercamos a un reemplazo de un proceso temporal y espacialmente extendido que termina por colapsar en su producto.

Se reconoce, desde luego, que en toda forma de reificación hay un componente cognitivo y que, por ello mismo, es tentador redescribirlas a todas como reificaciones en tanto concretizaciones. Empero, creemos que ello es equivocado porque habría ciertos tipos de reificación (la mereológica, la analógica y la de procesos) en los cuales el énfasis está en elementos contextuales ónticos y no sólo epistémicos o pragmáticos.

Esto último es importante porque la utilidad de una noción como la de reificación radica en la capacidad de crítica que moviliza. Esto es así porque los criterios de relevancia epistémica que poseemos son ellos mismos el resultado de un proceso histórico que los generó -y que suele desconocerse- y que viene acompañado, no lo olvidemos, de culturales materiales y de prácticas sociales que trascienden la polaridad abstracto-concreto.

En ese sentido sería importante no pasar por alto la posibilidad de que la reificación opere en 
esferas no representacionales $-y$, por ende, absolutamente ajenas a la polaridad abstracto-concreto que define a la reificación por concretización- por medio de inferencias materiales prácticas (Brandom 1994) o por medio de configuraciones de las culturas materiales -scaffoldings y affordances- y de las prácticas sociales (Estany \& Martínez 2013) que generan sesgos sistemáticos, quizás incluso agnogenéticos (Proctor \& Schiebinger 2008), que conducen a reificaciones analógicas que pasan inadvertidas; un ejemplo son los sesgos de género sistemáticos que producen las formas de educación, de producción y de reproducción modernos.

Estos sesgos de las prácticas podrían describirse también como fetichizaciones (à la Adorno) y reificaciones (à la Lukacs) concebidas en la tradición crítica, es decir, como supuestos elaborados en función de posicionamientos políticos y éticos, i.e. el lugar y la posición que tienen los agentes epistémicos frente a las víctimas de las estructuras desiguales y conflictivas del campo político, económico y cultural de la modernidad capitalista (Horkheimer 2004, Lukács 1970). En este caso nos referiremos a reificaciones implícitas.

\subsection{La reificación y sus vertientes socio-epistémicas}

La reflexión anterior en torno a los tipos de reificación ha dejado claro que lo que caracteriza a la misma es su dimensión perniciosa y metonímica. Sin embargo, ya sea que se le conciba como un vicio, como la violencia epistémica propia de nuestras abstracciones o como un elemento que opera encubierto en nuestra praxis, es claro que está asociada al saber declarativo -saber qué- o al saber procedimental -saber cómo-. Ello abre la posibilidad de interrogar a la reificación desde el punto de vista de la epistemología social, la sociología del conocimiento y la ética.

Así, en primera instancia se puede afirmar una verdad de perogrullo. Reificar requiere tener cierta familiaridad, es decir, cierta competencia sobre una práctica epistémica para así poder entender su lógica, pero también pareciera requerir cierta incompetencia ya que, de lo contrario, no queda claro en qué sentido es que se comete un acto pernicioso y metonímico que reemplaza a un todo por la parte, a un proceso por su producto, a un género por su especie o a un abstracto por un concreto. En todos estos casos dichos reemplazos operan dentro de un marco representacional con pretensiones de verdad que pretende describir una totalidad o, por otro lado, con respecto a una acción con pretensión de validez que se desenvuelve al interior o en relación a dicha totalidad. En ambos casos los sujetos son agentes epistémicos cuyas acciones están estructuradas sobre la base de una mínima comprensión de dicha totalidad.

Ahora bien, si la reificación sólo puede ser ejecutada y criticada por sujetos mínimamente competentes (aunque pueda ser reproducida como sentido común) y que se encuentran inmersos en prácticas cognitivas, entonces parece natural enfocarla vía un análisis socio-epistémico. Aquí podríamos recuperar el trabajo reciente de Harry Collins y Robert Evans (2009) sobre experticias, con el cual han distinguido entre experticias especialistas, por un lado, y meta-experticias, por otro. El primer tipo de experticia, las experticias especialistas, no se caracterizan en términos de la rareza o singularidad con la cual son encontradas al interior de una sociedad. Éstas pueden ser tan comunes que se juzguen como ubicuas -como la competencia lingüística que se tiene de la lengua materna en un país determinado en el que dicha lengua es oficial- o pueden ser tan infrecuentes que se juzguen como experticias interactivas o contributivas para una rama específica del conocimiento; en el caso de las experticias interactivas se comprenden los principios teóricos y el vocabulario de una disciplina y se puede, por ende, entablar una discusión con los expertos contributivos que poseen, además, un saber procedimental. En suma, las experticias especialistas remiten a competencias cognitivas en el plano discursivo y/o práctico que permiten una inter-acción con otros agentes de tal suerte que es posible una acción coordinada moldeada por fines, valores o normas comunes.

El segundo tipo de experticia, las meta-experticias, remiten por el contrario a competencias cognitivas sobre las jerarquías imperantes en el campo social constituido por los expertos mismos; remiten a un mapa de las estructuras desiguales, los juegos de poder y de la posibilidad de saber quién es quién en dicho campo. Se les puede caracterizar tanto en términos externalistas como internalistas. En el caso de las meta-experticias externalistas nos encontramos con una comprensión de un campo 
social que permite reconocer instituciones y referentes sociales que son confiables a la hora de indicar quién es un experto y quién no, quién de entre todos los expertos tiene más jerarquía, etc.; en este sentido, dichas experticias consisten en reconocer y avalar a las instancias que validan a los expertos.

Por otro lado, las meta-experticias internalistas presuponen una comprensión no únicamente de las instituciones de validación sino de las normas mismas que gobiernan dicha validación y de cómo dichas normas se aplican en casos concretos; presuponen, por ende, la posesión de una experticia interactiva o contributiva al interior de un campo. Usualmente esto último se traduce en una capacidad de reconocer y discriminar entre aquellos a los que uno considera sus pares y a aquellos a los que uno considera todavía aprendices; es decir, permite juzgar hacia abajo dada una jerarquía pero quizás no juzgar hacia arriba dada esa misma jerarquía.

Ahora bien, lo anterior permite introducir nuevas preguntas en lo que al tema de la reificación respecta. Por ejemplo, nos permite preguntarnos acerca de quién puede producir y reproducir una reificación y quién la sufre, la detecta; quién puede, asimismo, denunciarla. Parecería, en este sentido, que producir una reificación de cualquier tipo requiere mínimamente poseer una experticia especialista, sin importar si ésta es ubicua, interactiva o contributiva.

Por otro lado, reconocer que se ha cometido una reificación parece demandar mayores competencias. Esto es así porque reconocer que se ha cometido un acto pernicioso y metonímico requiere una capacidad de evaluar tanto (i) el desempeño propio y ajeno a la luz de las normas, valores y fines que estructuran nuestras competencias, (ii) el estado actual del conocimiento sobre un dominio dado y, (iii) tener una posición reconocida en las estructuras de poder del campo. Ello parece arrojarnos al terreno de las meta-experticias y pareciera que una vez allí no bastarán las aproximaciones externalistas toda vez que un señalamiento de reificación puede generar un conflicto al interior del campo de los expertos; es decir, aquel que señala la existencia de una instancia de reificación se coloca a sí mismo como un experto capaz de evaluar a otros que, por lo menos en este tema, no son percibidos como sus pares precisamente porque los segundos han cometido, sin notarlo, dicha falla. Y, dado que "idealmente" todos estos expertos tienen cierto grado de aval institucional, lo que restaría es necesariamente retrotraer la discusión al terreno mismo de los contenidos de una disciplina.

Sin embargo, dado que "históricamente" los campos de expertos no tienen el mismo poder y competencia política, la capacidad de reconocimiento de las reificaciones implica necesariamente una articulación entre los contenidos de un discurso -con especial énfasis en sus pretensiones de verdad- y las condiciones y luchas por la validez de dichos discursos. Aquí resulta relevante comprender los campos de experticias siguiendo a Pierre Bourdieu (1976), es decir, en tanto campos en los cuales los juegos de lenguaje están estructurados asimétricamente (hay diferencia en los capitales simbólicos, es decir, en las acumulaciones de reconocimientos sociales), esto por un lado, y, por otro lado, campos igualmente estructurados en función de luchas de poder que buscan afianzar la autoridad epistémica de los expertos para así incidir en diversos debates sociales.

$\mathrm{Si}$ a estas consideraciones sociológicas de la reificación se les sitúa históricamente, entonces es posible pensar la crítica a las reificaciones como un señalamiento socioepistémico de una falla en las competencias de los agentes involucrados en estos proyectos explicativos. Sin embargo, dicho señalamiento trasciende la esfera de validez científica si se le define de forma amplia al incluir a aquellos que se han visto afectados por los efectos, tecnologías y normas generados por dichos discursos, y por ello no suele ser una crítica puramente epistémica, sino más bien una crítica a la validez y legitimidad de la autoridad de dichas instancias.

Por esto último reconocer una reificación implica reconocer un conflicto mas no necesariamente dirimirlo; esto, dicho sea de paso, implica una concepción agonista de la epistemología social y no una concepción deliberativista de la misma, como suele ser el caso en la tradición analítica sajona. Ello porque el señalamiento de que una reificación ha ocurrido implica el surgimiento público de un conflicto -lo que en el campo de los estudios Ciencia, Tecnología y Sociedad (CTS) suele llamarse una controversia-. Dicho conflicto o controversia puede ser reconocida externamente sólo si los expertos gozan de un aval institucional y una cierta simetría en la jerarquía del campo. Empero, reconocer dicho conflicto no implica que se reconozca que la reificación ha de facto ocurrido. Tomar partida requiere 
una experticia interactiva o contributiva que pueda mantener su validez social en medio de una polémica; pero la resolución de dicha controversia conlleva eventualmente una reorganización de cierto campo social. Si el acusador convence (en un sentido internalista) y/o vence (en un sentido externalista) al resto de los expertos, se coloca a sí mismo a la cabeza de la jerarquía; mas, si fracasa, puede ser incluso expulsado del campo.

Todo lo anterior nos permite distinguir entre las facetas socio-epistémicas de la reificación, que remiten al espacio común de dar y pedir razones, gobernado por normas, valores y fines colectivamente reconocidos e institucionalmente avalados, y que remite al problema de la validez de las axiologías vigentes y al problema del mutuo reconocimiento de las experticias. Señalar una reificación implica, por tanto, la posibilidad de poner en jaque a la validez de dichas axiologías y al mutuo reconocimiento y simetría de dichas experticias.

\section{Reificación en los desafíos de la Inter y Transdisciplinariedad}

Llegados a este punto, con el aparato analítico ya trazado, nos es posible remontar al inicio de este texto justamente para señalar la importancia que habrá de tener el concepto de reificación para una epistemología social y política que permita llevar a cabo tanto una crítica de las ontologías y epistemologías de la biología como de la estructura de los campos, discursos e instituciones que, o bien son parte de ella, o bien interactúan con ella.

Esta tarea, sin embargo, no irrumpe en un espacio vacío sino que necesariamente dialoga y se posiciona ante propuestas ya existentes que han buscado soluciones estructurales, de corte inter o transdisciplinario, a los problemas ontológicos y/o epistemológicos de la biología.

Nosotros queremos resaltar dos tendencias muy generales sobre esta unidad o articulación de saberes y prácticas: por un lado, aquellas que hacen énfasis en las articulaciones semánticas de las disciplinas y, por otro, aquellas que ahondan en su dimensión práctica y social. ${ }^{1}$ Para el caso de la tendencia semántica podemos ubicarla como heredera de sesgos empiristas donde se separan los contextos de justificación y de descubrimiento, concentrándose todavía en la unidad de la ciencia concebida a modo de relaciones intra e interteóricas que son posibles, coherentes y traducibles entre campos semánticos. Por su parte, una concepción social e histórica de las prácticas científicas puede ubicarse como una posición crítica y escéptica de esta unidad semántica, en tanto que es más cercana a estudios históricos, políticos y antropológicos de la ciencia donde se vuelven centrales las polémicas y crisis al interior de las organizaciones y estructuras científicas, y entre las diversas racionalidades que se juegan en las investigaciones inter-transdisciplinarias.

Si bien ambas tendencias pueden entenderse de manera articulada, es decir, entendiendo el trabajo disciplinar como redes de modelos ancladas a espacios sociales dinámicos de agencias y procedimientos de validez y aplicación de conocimientos, la distinción entre perspectivas semánticas y prácticas sigue siendo útil para comprender los sesgos que operan en los estudios inter-transdisciplinarios. Es el caso para algunas investigaciones biológicas o sociales, que suelen plantearse horizontes unificadores o integracionistas sobre problemas sociales, los cuales oscilan entre posiciones semánticas extremas que incluyen enfoques reductivos fisicalistas o biologicistas. Por otro lado, podemos encontrar relativismos o pluralismos que plantean la imposibilidad de articulaciones disciplinares y despojan a los sujetos de sus materialidades físico-biológicas y los arrojan a una diferencia irresoluble.

La categoría de reificación aporta un aparato crítico para distinguir y ponderar estas visiones, así como para señalar los desafíos que implica un diálogo (énfasis semántico) y articulación (énfasis práctico) de saberes. A continuación planteamos estas posibilidades y proponemos un horizonte posible para articulación entre reificación y articulación disciplinar.

\footnotetext{
${ }^{1}$ Estas dos visiones sobre la inter-transdsiciplina pueden corresponderse con algunas propuestas mucho más elaboradas. Katri Huutoniemi et al. (2010) por ejemplo han propuesto una serie de indicadores y categorías que permiten entender la investigación interdisciplinaria en función de 1) las perspectivas sobre lo que es integrado, 2) sobre el tipo de interacciones, o cómo se hace y finalmente 3) el tipo de metas que origina la investigación inter-transdisciplinaria. Estos autores además postulan tres tipos de interacciones multidisciplinarias: enciclopédica, contextualizante, compuesta; y tres interdisciplinarias: empírica, metodológica y teorética.
} 


\subsection{Reificación en una visión ingenua de la integración disciplinar}

Los diversos enfoques de integración que se proponen, desde la inter hasta la transdisciplinariedad plantean diversas discusiones sobre el tipo de síntesis que se busca, la delimitación y definición de las disciplinas y el tipo de cooperaciones que implica (Aboelela et al. 2007). Para un enfoque preeminentemente semántico la articulación de las disciplinas estaría mediada por su capacidad epistémica para generar nuevos conceptos, categorías o modelos que puedan cubrir exigencias de cada comunidad de lenguaje. En este sentido, una investigación transdisciplinaria se enmarcaría dentro de un intento por afirmar un lenguaje de carácter universal, i.e. conceptos o modelos que logran atravesar fronteras disciplinares y guardar sus contenidos de verdad.

Una visión semántica no necesita asumir compromisos ontológicos o metafísicos mientras que su contenido veritativo quede aceptado por sus contextos semánticos. Así, la validez de un término o concepto inter-transdisciplinario irá en función de la capacidad de las comunidades epistémicas para aceptar o subsumir dichos conceptos en la red semántica que constituye su campo. En este sentido lo propio de la transdisciplina sería el poder constituir estructuras o modelos "puente" que permitan a cada campo incluir y reconocer mutuamente sus ontologías (por ejemplo otros niveles de realidad) y sus modelos sobre la complejidad ontológica de los sistemas biológicos y sociales (Morín 1998).

Estas visiones pueden reconocer los efectos y las dinámicas sociales que genera un modo disciplinar de conocimiento, pero mantienen la intuición de fondo de que el mecanismo necesario y viable para superar la hiperespecialización disciplinaria gira en función de una creciente unidad semántica, es decir de un mayor entendimiento entre diversas comunidades de lenguaje para abordar problemas epistémicos comunes. Llamamos a esta una perspectiva ingenua sobre la unidad de las ciencias porque no es capaz de reconocer y enfrentar los obstáculos y polémicas ontológicas, hermenéuticas, políticas y económicas que recorren las consideraciones semánticas.

El problema reside en el supuesto de que las ontologías, modelos e intervenciones pueden ser compatibles y resueltos sólo con condiciones comunicativas, es decir, ésta sería una concepción deliberativista de las dinámicas socio-epistémicas en la cual se apuesta por valores como la apertura y la tolerancia o en lo que podría ser un diálogo semántico y metodológico abierto pero que supone, sin discutir, la permanencia y división institucional del trabajo científico dominante. Los usos y abusos lógicos y semánticos se resuelven en ese ámbito: como competencias entre modelos o categorías al interior del campo, multi-disciplinariamente como diálogo entre comunidades, o intertransdisciplinariamente como generación de nuevos lenguajes que nazcan entre comunidades (Aboelela et al. 2007).

En esta visión ingenua podemos ubicar algunas tesis naturalistas que suponen una visión articulada del mundo biológico con el mundo social, donde las categorías de las ciencias naturales comienzan a "esclarecer" los terrenos "ambiguos" y "equívocos" de las humanidades y las ciencias sociales, contribuyendo así a una "biologización" del sujeto de la política, la cultura y la economía, y un entendimiento "científico" de los procesos civilizatorios.

La ingenuidad de estas tendencias radica en que no son capaces, por un lado, de rebasar una noción hiperclásica de la epistemología y el conocimiento y, por otro, en la falta de un aparato analítico que logre situar a la ciencia más allá de las redes semánticas y de las comunidades de lenguaje que las construyen, es decir, se es incapaz de reconocer que no sólo somos sujetos de lenguaje sino también de vida y, por lo tanto, de necesidades, desigualdades, luchas políticas y contradicciones económicas.

La reificación como categoría normativa de los términos, modelos y teorías científicas recupera las críticas a la universalidad de las ontologías y por ello los problemas de traducibilidad, comunicabilidad e inconmensurabilidad semántica de los términos científicos. En este sentido, la reificación permite indicar i) aquellos conceptos o modelos que se han cerrado a discusiones y transformaciones del campo comunicativo en que nacen; ii) los abusos de estas comunidades de lenguaje cuando vuelven verdades a sus metáforas; y iii) las repercusiones de estos abusos en la vida material de poblaciones y ecosistemas concretos. Así la transdisciplinariedad no puede ser sólo un diálogo simétrico para construir una visión 
común del objeto, sino que exige recuperar las condiciones materiales de producción de conocimiento; es decir, las capacidades y posiciones diferentes de los agentes involucrados. Estas consideraciones son de orden pragmático y confirman que la ciencia y las reificaciones deben entenderse también en función sus condiciones sociales, históricas, políticas y económicas.

\subsection{Transdisciplinariedad y reificación: visión polémica de las articulaciones científicas}

Entendemos por posiciones polémicas de las articulaciones e integraciones disciplinares a aquellas discusiones que enfatizan los problemas de índole metodológico y de cooperación social, donde la posible unidad está mediada por condiciones prácticas entre los investigadores de distintas disciplinas, no reducibles a ningún tipo de lenguaje o modelo más "universal". Estas visiones afirman la idea de que tanto los agentes como los saberes sólo se pueden estructurar y poner en interacción sus aparatos tecnológicos y conceptuales si éstas también reconocen sus bases institucionales (Peláez \& Suárez 2010).

Un elemento que distingue a estas visiones, es el reconocimiento creciente del carácter político y axiológico de las ciencias y la crítica a las demarcaciones entre la esfera humanista y la científica (Klein et al. 2004).

Las consideraciones sociológicas sobre la reificación, a saber: aquellas relacionadas con el quién, cuándo y qué efectos tiene indicar o señalar las reificaciones, se vuelven elementos clave para superar una visión ingenua de la articulación entre ciencias sociales, naturales y humanidades. Una tesis central en el problema de la transdisciplinariedad es que las comunidades epistémicas deben suponerse como estructuras desiguales, donde no puede suponerse la simetría de los hablantes y argumentantes: esto trastoca y muchas veces impide la realización de un dialogo inter o transdisciplinar. Si la transciplinariedad nace como una forma de superar las hiperespecializaciones y reificaciones de cada campo, su superación exige algo más que consideraciones epistémicas: exige una lucha política para que las voces que critican las reificaciones al interior o entre investigaciones intedisciplinarias sean efectivamente tomadas en cuenta.

Y es que cuando consideramos a las disciplinas no sólo como comunidades epistémicas, sino como campos gobernados también por dinámicas de luchas de poder, por estructuras desiguales y principios no explícitos, el problema de la reificación adquiere una connotación política: ¿Quién habla a nombre de una disciplina? ¿Quién dialoga en la transdisciplina? ¿Cómo puede transformarse la estructura social del campo? ¿Qué modelos representan a un campo biológico? ¿Qué visiones se ocultan y se soslayan cuando se dialoga entre modelos sobre el mundo bio-social?

El reconocimiento de estas contradicciones sociales al interior y entre disciplinas no niega su posible diálogo o articulación, sino que abre la discusión meta-científica sobre las dinámicas históricas y sociales de las instituciones científicas. Un ejemplo de esto es el modo en que Adrian Panofsy (2011) recupera la noción de campo científico formulada por Pierre Bourdieu y en la cual se incorporan conceptos y relaciones sociológicas claves para entender el espacio interdisciplinar, a saber: luchas de poder, capitales científicos, dinámicas de juego. El campo interdisciplinar, a diferencia de los campos intra-disciplinares, estaría caracterizado por la ausencia de un monopolio del poder, i.e. de la autoridad científica y, por lo tanto, como un espacio que presenta una lucha propia por la distribución y definición de sus múltiples capitales y tasas de recambio.

Las críticas a las reificaciones se vuelven entonces no sólo categorías normativas de los abusos semánticos y ontológicos, sino también indicadores de aquellas tendencias que gobiernan cada campo disciplinar y las posibilidades de interacción. Un itinerario necesario para analizar la reificación al interior y entre disciplinas implicaría peinar las categorías, modelos y aplicaciones a contrapelo (à la Benjamin), es decir, contrastar los conceptos, modelos y explicaciones dominantes al interior de un campo, con aquellas voces y agentes soslayados o minoritarios que participan sin el capital de los grandes jugadores. La reificación entre disciplinas, es decir aquellas que se juegan en explicaciones con pretensión inter o transdisciplinaria deben ubicarse no sólo en función de los agentes científicos, sino en función del contexto social y cultural donde se gestan. Es en este sentido que la reificación no puede ser criticada sólo por el experto, sino también por aquellas víctimas afectadas por la imposición 
de un cierto tipo de modelo, estrategia o programa científico.

\subsection{Hacia una visión de la transdisciplinariedad como estrategia de transformación democrática}

En el apartado anterior hemos visto que la transdisciplinariedad exige la incorporación de las categorías pragmáticas del conocimiento. Pero, cómo podemos entender la transdisciplinariedad como una estrategia que permite la realización de una mejor comprensión e intervención sobre el mundo bio-social. A continuación formulamos cinco tesis que resumen nuestra propuesta antireificacionista de la transdisciplinariedad.

I. La transdisciplinariedad nace como una respuesta a necesidades concretas de comunidades de vida y de lenguaje. Esto implica un tipo de racionalidad ética, que asume una responsabilidad con los afectados para regular la eficiencia de los medios y la prudencia de los fines.

II. La transdisciplinariedad rechaza la crueldad y la violencia de las ontologías y epistemologías que sirven para la reproducción de la carencia y la dominación. La transdisciplinariedad construye, usa y transforma los conocimientos científicos sobre el mundo biológico y social, desde el reconocimiento de la anterioridad cultural y para el cumplimiento ético de su investigación.

III. La transdisciplinariedad exige un espacio democrático de diálogo entre discursos con pretensiones de verdad y validez, así como una capacidad de reconocimiento entre diversos sujetos y agencias que tienen diversas experticias y modos de razonamiento (ético, epistémico, técnico y prudencial). Por eso, la transdisciplinariedad plantea un postulado de justicia formal: que haya simetría comunicativa y material: que los interlocutores tengan las condiciones materiales para hablar. Es aquí donde nacen los conflictos y las polémicas entre capitales simbólicos y materiales. La transdisciplinariedad es la búsqueda de la resolución de estas diferencias y desigualdades discursivas en función del consenso de un programa de bienestar social.

IV. La transdisciplinariedad es una estrategia de lucha contra aquellos procesos, dinámicas y agentes que niegan el diálogo simétrico, la responsabilidad frente a las víctimas, la capacidad argumentativa y la realización efectiva de bienestar común. La diversidad de demandas, necesidades y criterios puede organizarse políticamente en función de demandas que funcionen momentáneamente como equivalentes universales para la institución de acciones de transformación.

V. Finalmente, la transdisciplinariedad, informada por la noción de reificación en sus dimensiones socio-epistémicas, permite combatir injusticias epistémicas (Fricker 2007), sean éstas hermenéuticas (de autoconocimiento) o testimoniales, de tal suerte que sea posible consolidar una justicia epistémica que reconozca la relevancia de las culturas materiales, en tanto andamiajes institucionales, pedagógicos, políticos, técnicos, etc. Esto último es fundamental ya que permite justiciar, es decir, hacer aplicable, una justicia epistémica de corte contributivo en las cuales la ciencia y la tecnología no sean vistas como prácticas propias del Primer Mundo o de las grandes urbes del planeta sino que se reconozca que la creación de conocimientos se da en todo contexto y que, por ello mismo, nos enfrentamos al reto de poder incidir en la axiología y en la práctica de la ciencia y la tecnología no sólo como consumidores o beneficiarios sino como agentes creativos. Asimismo, eso evita caer en una visión meramente distributiva, gobernada por el mercado o la filantropía, en la cual la ciencia y la tecnología son regalos, productos o caridades venidas de fuera. Permite, por último, una justicia retributiva y conmutativa que evite el saqueo de materias primas, saberes tradicionales y prácticas milenarias de los pueblos originarios de nuestra América para que, en vez de que éstos sean despojados, logren beneficiarse de sus propias producciones culturales. 


\section{Conclusión}

Como podemos ver nuestro enfoque sobre la transdisciplinariedad y la reificación en la biología agrega una condición necesaria para que las diversas posibilidades integracionistas y pluralistas converjan: los problemas biológicos-sociales que hoy figuran en el itinerario de las ciencias biológicas, biomédicas y sociales, pueden ser considerados como problemas complejos en tanto que la mayoría tienen definiciones polémicas y estrategias de resolución diversas.

Nuestra propuesta indica que estos problemas pueden abordarse en tanto que se escuchen y analicen las críticas que nacen a partir del acto de reificar los supuestos, modelos y categorías empleados. La noción de reificación puede servir así como un nodo articulador que permita poner en diálogo las dimensiones sociales del sujeto que produce y consume el conocimiento, por un lado, con las preguntas más clásicas de la metafísica y la epistemología, por otro.

La posibilidad de un diálogo, integración o articulación entre disciplinas biológicas y sociales, exige una visión a contrapelo de las narrativas y luchas de poder que ocurren en los campos científicos: al interior de un campo científico, que serían los debates intradisciplinarios sobre los paradigmas o modelos dominantes; entre campos científicos, que serían los debates interdisciplinarios sobre la lucha por la autoridad y la experticia social y finalmente entre campos sociales y estrategias transdisciplinarias donde la voz y la interpelación contra las reificaciones pueden provenir de afectados que viven más allá de los campos y experticias científicas.

Bibliografía

Aboelela, S.W., Larson, E., Bakken, S., Carrasquillo, O., Formicola, A., Glied, S.A. y K.M. Gebbie (2007), "Defining Interdisciplinary Research: Conclusions from a Critical Review of the Literature”, Health Services Research 42(1p1): 329-346.

Bainbridge, W.S. (2006), Managing Nano-Bio-Info-Cogno Innovations: Converging Technologies in Society, Dordrecht: Springer.

Bewes, T. (2002), Reification: or the Anxiety of Late Capitalism, London: Verso.

Brandom, R. (1994), Making It Explicit. Reasoning, Representing and Discursive Commitment, Cambridge: Harvard University Press.

Bourdieu, P. (1976), El campo científico, en los usos sociales de la ciencia, Buenos Aires: Nueva Visión.

Collins, H. y R. Evans (2009), Rethinking Expertise, Chicago: University of Chicago Press.

Dupré, J. (2012), Processes of Life. Essays in the Philosophy of Biology, Oxford: Oxford University Press.

Dussel, E. (1993), Las metáforas teológicas de Marx, Estella-Navarra: Verbo Divino.

Dussel, E. (2009), Política de la liberación II. Arquitectónica, Madrid: Trotta.

Estany, A. y S. Martínez (2013), “'Scaffolding' and 'Affordance' as Integrative Concepts in the Cognitive Sciences”, Philosophical Psychology 27(1): 98-111.

Fricker, M. (2007), Epistemic Injustice: Power and the Ethics of Knowing, Nueva York: Oxford University Press.

Friedman, M. (1974), “Explanation and Scientific Understanding”, Journal of Philosophy 71: 5-19.

Hacking, I. (2009), Scientific Reason, Taipei: National Taiwan University Press.

Honneth, A., Butler, J., Geuss, R., Lear, J. y M. Jay (2012), Reification: a New Look at an Old Idea, Oxford: Oxford University Press.

Horkheimer, M. (2004), Teoria critica, Madrid: Amorrortu.

Huutoniemi, K., Klein, J.T., Bruun, H. y J. Hukkinen (2010), “Analyzing Interdisciplinarity: Typology and Indicators”, Research Policy 39(1): 79-88. 
Kaplan, J.M. y R.G. Winther (2012), "Prisoners of Abstraction? The Theory and Measure of Genetic Variation, and the Very Concept of 'Race”, Biological Theory 7(4): 401-412.

Kitcher, P. (1989), "Explanatory Unification and the Causal Structure of the World”, en Kitcher, P. y W. Salmon (eds.), Scientific Explanation, Minneapolis: University of Minnesota Press, pp. 410-505.

Klein, J.T., Grossenbacher-Mansuy, W., Häberli, R., Bill, A., Scholz, R.W. y M. Welti (eds.) (2004), Transdisciplinarity: Joint Problem Solving among Science, Technology, and Society-An Effective Way for Managing Complexity, Birkhäuser: Basel.

Levins, R. (2006), “Strategies of Abstraction”, Biology $\mathcal{G}$ Philosophy 21(5): 741-755.

Levins, R. y R. Lewontin (1987), The Dialectical Biologist, Cambridge: Harvard University Press.

Lukács, G. (1970), Historia y conciencia de clase: estudios de dialéctica marxista, La Habana: Editorial de Ciencias Sociales del Instituto del Libro.

Marx, K. (1991), El capital: crítica de la economía política, México: Siglo XXI.

Mitchell, S. (2003), Biological Complexity and Integrative Pluralism, Nueva York: Cambridge University Press.

Morin, E. (1998), Introducción al pensamiento complejo, Barcelona: Gedisa.

Panofsky, A. (2011), "Field Analysis and Interdisciplinary Science: Scientific Capital Exchange in Behavior Genetics", Minerva 49(3): 295-316.

Peláez, Á.J. y R. Suárez (2010), Observaciones filosóficas en torno a la transdisciplinariedad, México: Anthropos.

Proctor, R. y L. Schiebinger (eds.) (2008), Agnotology: The Making and Unmaking of Ignorance, Stanford: Stanford University Press.

Winther, R.G. (2006a), "Fisherian and Wrightian Perspectives in Evolutionary Genetics and Model-Mediated Imposition of Theoretical Assumptions”, Journal of Theoretical Biology 240: 218-232.

Winther, R.G. (2006b), “On the Dangers of Making Scientific Models Ontologically Independent: Taking Ricard Levin's Warnings Seriously”, Biology and Philosophy 21: 703-724.

Winther, R.G. (2011a), “Consciousness Modeled: Reification and Promising Pluralism”, Pensamiento 67(254): 617630 .

Winther, R.G. (2011b), "Part-whole Science”, Synthese 178: 397-427.

Winther, R.G. (2014a), "James and Dewey on Abstraction”, The Pluralist 9(2): 1-28.

Winther, R.G. (2014b), “The Genetic Reification of 'Race'? A Story of Two Mathematical Methods”, Critical Philosophy of Race 2(2): 204-223. 